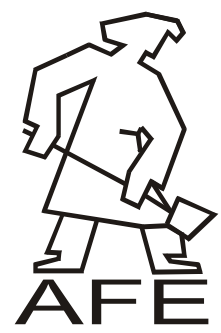

ARCHIVES

of

FOUNDRY ENGINEERING

ISSN (2299-2944)

DOI: $10.2478 / \mathrm{v} 10266-012-0095-9$

Volume 12

Issue $3 / 2012$

\title{
Comparison of Energy Consumption in the Classical (PID) and Fuzzy Control of Foundry Resistance Furnace
}

\author{
E. Ziółkowski ${ }^{a}$, P. Śmierciak \\ AGH University of Science and Technology, Faculty of Foundry Engineering, Cracow, Poland \\ *Contact for correspondence: e-mail: ez@agh.edu.pl
}

Received 16.04.2012; accepted in revised form 02.07.2012

\begin{abstract}
Foundry resistance furnaces are thermal devices with a relatively large time delay in their response to a change in power parameters. Commonly used in automation classical PID controllers do not meet the requirements of high-quality control. Developed in recent years, fuzzy control theory is increasingly being used in various branches of economy and industry. Fuzzy controllers allow to introduce new developments in control systems of foundry furnaces as well. Correctly selected fuzzy controller can significantly reduce energy consumption in a controlled thermal process of heating equipment. The article presents a comparison of energy consumption by control system of foundry resistance furnace, equipped with either a PID controller or fuzzy controller optimally chosen.
\end{abstract}

Keywords: Automation of foundry processes, Control of foundry furnaces, PID and fuzzy controllers

\section{Introduction}

In order to design the control system of resistance of foundry furnace it is necessary to know the dynamic characteristics of the furnace, usually described as a transfer function $\mathrm{G}(\mathrm{s})$. For a given transfer function of such a furnace control system is chosen for the assumed structure and well-defined parameters. The article presents the stages of designing controllers for a resistance foundry furnace with transmittance

$G(s)=\frac{e^{-80 s}}{40000 s^{2}+370 s+1}$

Figure 1 shows the graph changes of temperature in the furnace chamber after enabling maximum output power of 150 $\mathrm{kW}$. For a given dynamic characteristics of foundry furnace will be selected classical PID and fuzzy controller for the assumed internal structure.

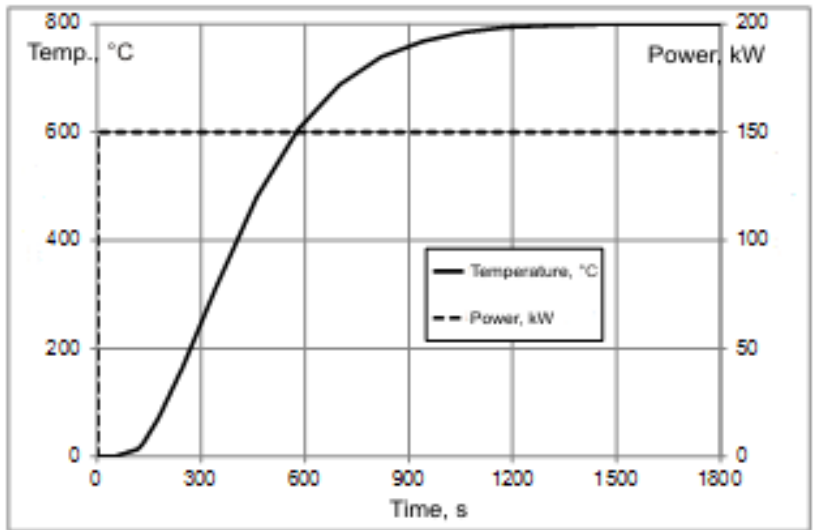

Fig. 1. Graph temperature changes in the resistance foundry furnace chamber when you turn on the maximum power supply 


\section{The control system with classical PID controller}

Diagram of the classical control system with negative feedback and PID controller, modelled in MATLAB / Simulink, shown in Figure 2. In order to allow the comparison of energy consumption of the two designed control systems the objects resistance furnace and regulators have been scaled. The possibility of temperature programming has been taking into consideration and it was assumed that the furnace is controlled by a PID controller without overshoot.

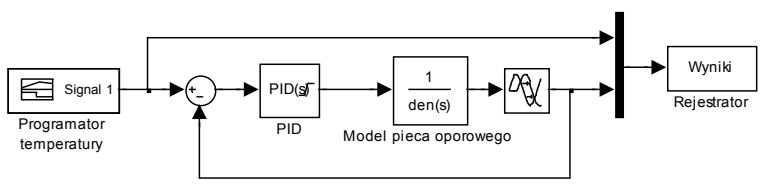

Fig. 2. Modeled in MATLAB / Simulink resistance furnace control system with PID controller

The procedure for auto-tuning PID controller, included in the program Simulink, calculated the following optimal values of the parameters of the controller:

- gain of the proportional term $\mathrm{k}_{\mathrm{P}}=2.2475$,

- gain of the integraf term $\mathrm{k}_{\mathrm{I}}=0.0056$,

- gain of the derivative term $\mathrm{k}_{\mathrm{D}}=215.9919$.

Figure 3 shows an simulation example of the control system with classical PID controller for an assumed normalized of temperature in the chamber of resistance furnace.

\section{The control system with fuzzy controller for the assumed structure}

Fuzzy control is becoming more widely used method of automatic control of systems.

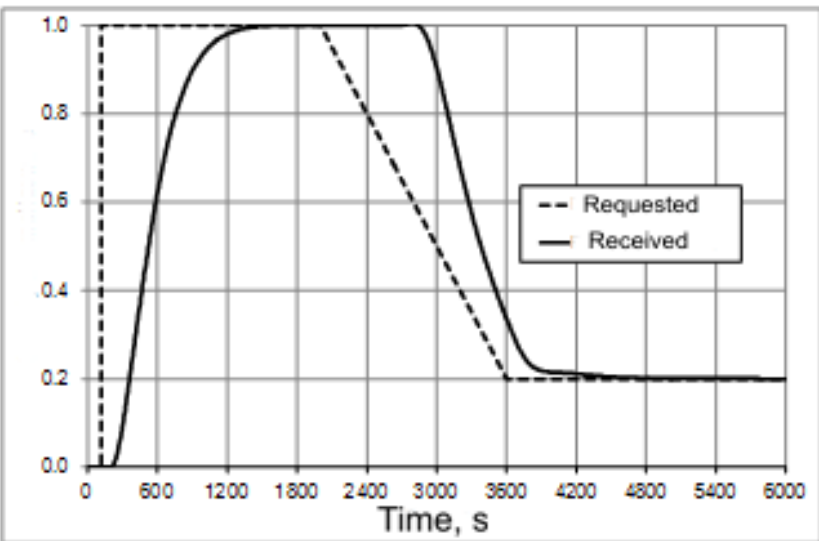

Fig. 3. Diagram changes of scaled temperature in the chamber of resistance furnace in the system with optimally selected parameters for PID controller
The theory and practical applications of fuzzy control can be found among others in the works [1-3]. Figure 4 shows an example - modelled in Simulink - of control system of resistance furnace using fuzzy controller. In this system, due to the large inertia of the object the Smith predictor has been used.

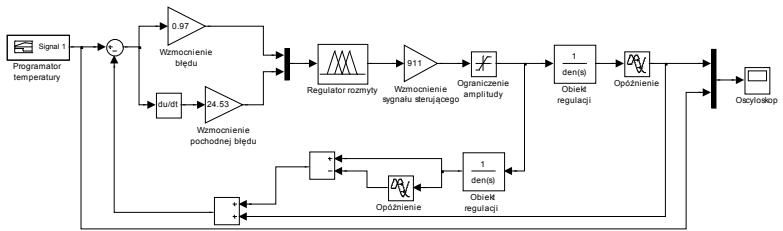

Fig. 4. Diagram of the resistance furnace control with fuzzy controller and Smith predictor

Fuzzy controller, used in the control system, has established an internal structure, by adopting the membership function for input signals (error signal, derivative signal of temperature and temperature error in the studied system) and the output signal that controls the resistance furnace. The controller has a set of 9, 25, 49 and 81 base rules specified in Mamdani-type fuzzy controller. The same set up for all the standard input membership functions is defined in Simulink by using procedure "fuzzy" (Fuzzy Logic Toolbox package [6]) and shown in Figure 5

Tuning the fuzzy controller so defined is to determine the optimal values of gains on both inputs and the output $[4,5]$. Optimization criterion usually takes one of the four formulas:

$$
\begin{aligned}
K & =\int|u(t)| d t \\
K & =\int|u(t)| t d t \\
K & =\int u(t)^{2} d t \\
K & =\int u(t)^{2} t d t
\end{aligned}
$$

The lower $\mathrm{K}$ value of this criterion , the more response of the control system is compatible with the desired course in the controls.

Determination of the fuzzy controller parameters can be achieved by various methods, for example by:

$$
\begin{array}{ll}
\text { - } & \text { simple search method [5], } \\
\text { - } & \text { genetic algorithm [4 5], } \\
\text { - } & \text { using artificial neural network [5]. }
\end{array}
$$

The criteria of quality control could be a measure of energy consumption of the control system, for example, resistance furnace. The regulator, for which the value of quality criterion $\mathrm{K}$ is higher, will be working in the system consuming more energy feeding the furnace

Figure 5 shows a diagram designed in Simulink system to compare the control quality using both PID and fuzzy controller. In this circuit the criterion of quality control in the form (2) has been assumed. Simulation results of both control systems are shown in Figure 6 

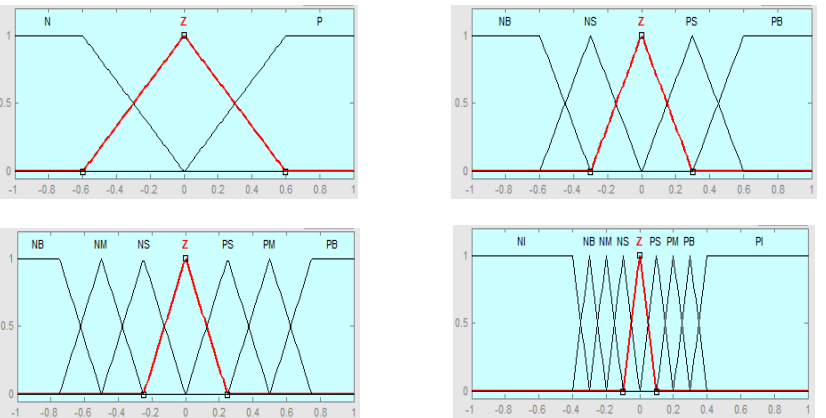

Fig. 5. The membership functions defined in Simulink for the Mamdani-type controller with 9, 25, 49 and 81 rules

The analysis of simulation results, shown in Figure 7 indicates that energy consumption in the control system with PID controller, despite the selection of the optimal values of its parameters, is higher than in the case of fuzzy control system with the assumed internal structure and optimally selected values of gains. The value of criterion $\mathrm{K}$ for PID control system was 701.4, while for the system with fuzzy controller was 384.1. The difference of these values is a result of different responses in the controls used to reduce the required temperature of the maximum level to $20 \%$ of the maximum temperature. PID controller with more than 12 minutes late response started to change the desired temperature, then the second level has been established temperature of about 8 minutes late. In the system of fuzzy controller to keep up with the temperature set up was almost immediate. Stage heating furnace to the nominal temperature in both cases was identical, reflecting the power of resistance furnace with a maximum available power

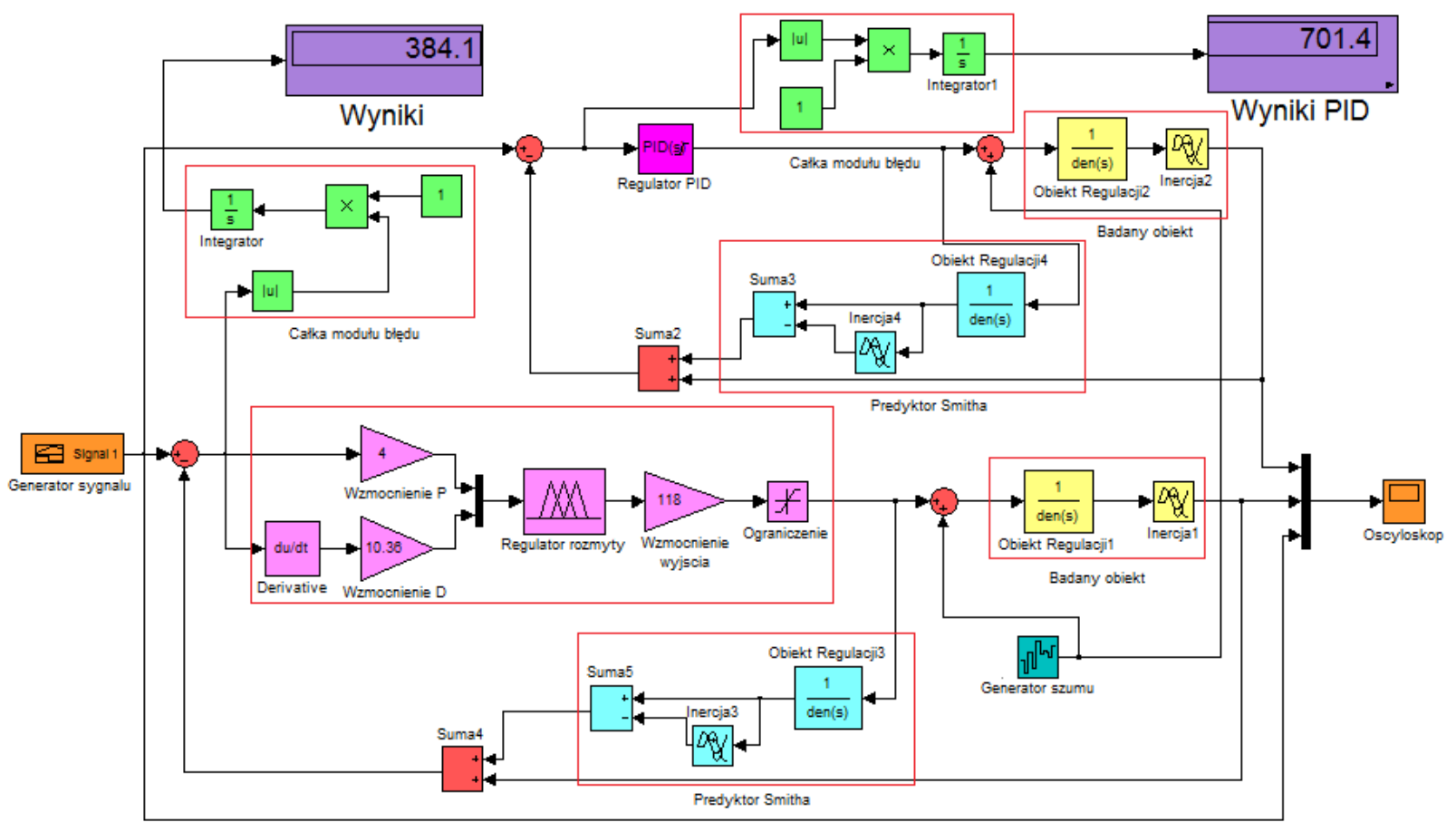

Fig. 6. Scheme designed in Simulink system simulation to compare the control quality criterion K, calculated according to equation (2), for the system with PID controller and fuzzy controller for the assumed internal structure

\section{SUMMARY}

Control of foundry furnaces, characterized by a very late reaction to the change in power parameters, can be successfully achieved by means of fuzzy controllers. The variety of internal structure, and sometimes very large number of parameters that define the action of these regulators make it necessary to use advanced methods of tuning of these controllers. Calculation of the fuzzy controller parameters can be achieved with the use of genetic algorithms and artificial neural networks. Using these methods optimally tuned of control systems better reflect the required changes of the temperature in the chamber of foundry furnace, than optimally tuned PID controllers. The optimization criterion for selection of the fuzzy controller parameters can also be proposed as the energy consumption of the control system.

Optimally designed fuzzy control system, in this case the resistance foundry furnace enables significant, comparing to the conventional control system with PID controller, reduction of energy consumption for process heat, so one can expect more organizational, economic and environmental benefits for foundries. 

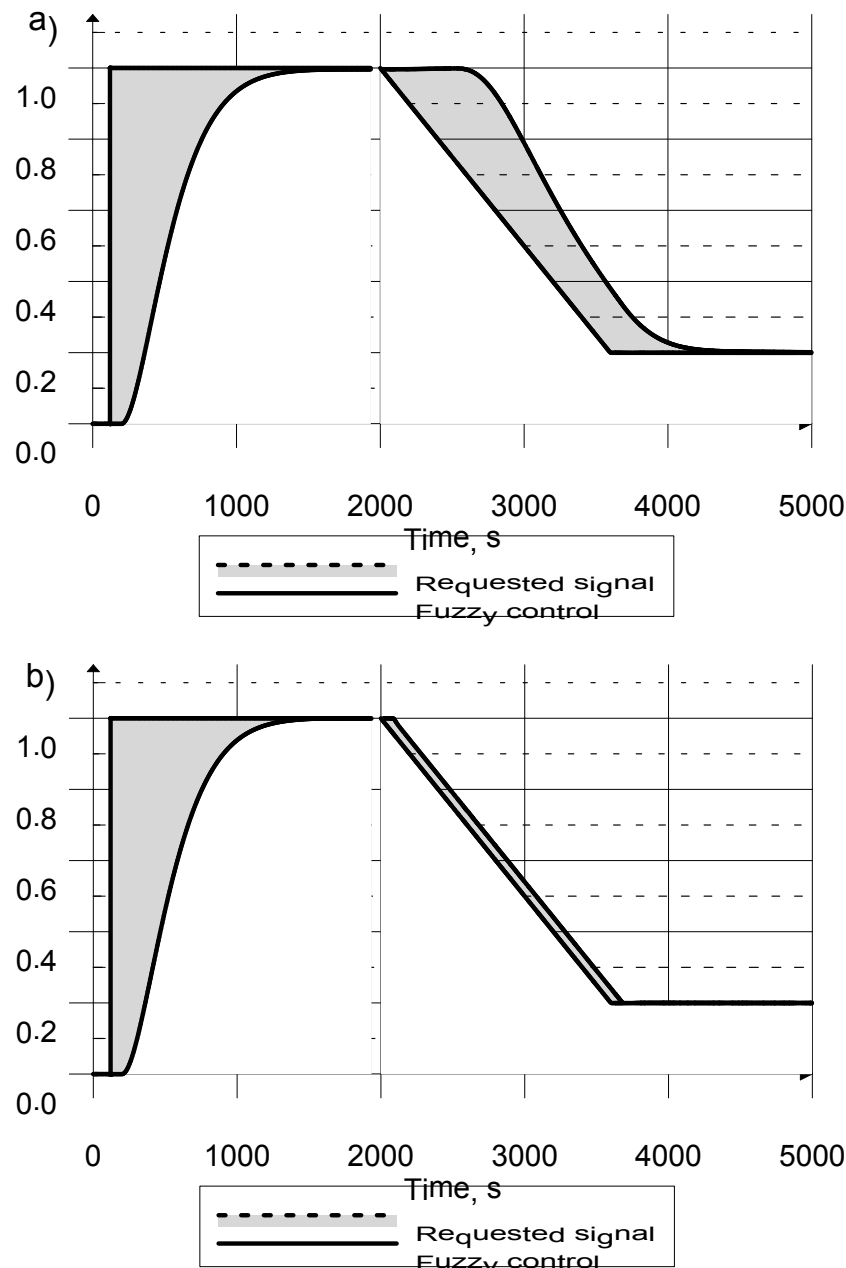

Fig. 7. The simulation results of the control response for optimal controller parameters and the selected area differential reference signal and obtained: a) for the system with PID controller, b) for fuzzy control system with the assumed internal structure

\section{Acknowledgments}

Calculations were performed using MATLAB / Simulink with Fuzzy Toolbox library on the computers of Wroclaw Centre for Networking and Supercomputing (www.wcss.wroc.pl), grant calculation No. 212

The work financed by under the contract with Ministry of Science and Higher Education No. 15.11.170.448.

\section{References}

[1] Yager, R.R. \& Filev, D.P. (1995). Podstawy modelowania $i$ sterowania rozmytego. WNT, Warszawa.

[2] Piegat, A. (1999). Modelowanie i sterowanie rozmyte. EXIT, Warszawa.

[3] Kacprzyk, J. (2001). Wieloetapowe sterowanie rozmyte. WNT, Warszawa.

[4] Byrne, J.P. (2003). GA-Optimisation of a Fuzzy Logic Controller. School of Electronic Engineering.

[5] Mrozek B. (2006). Projektowanie regulatorów rozmytych w środowisku MATLAB-Simulink. Pomiary Automatyka Robotyka. (11)( 5-12).

[6] The Math Works. Fuzzy Logic Toolbox. User's Guide. 